\title{
Assessment of Pain Sensitivity in Patients With Chronic Low Back Pain and Association With HTR2A Gene Polymorphism
}

\author{
Saliha Handan YILDIZ, ${ }^{1}$ Alper Murat ULAŞLI, ${ }^{2}$ Müjgan ÖZDEMİR ERDOĞAN, ${ }^{1}$ Ömer DİKİCİ, \\ Evrim Suna ARIKAN TERZİ, ${ }^{1}$ Ümit DÜNDAR, ${ }^{2}$ Mustafa SOLAK ${ }^{1}$ \\ ${ }^{1}$ Department of Medical Genetics, Medical Faculty of Afyon Kocatepe University, Afyonkarahisar, Turkey \\ ${ }^{2}$ Department of Physical Medicine and Rehabilitation, Medical Faculty of Afyon Kocatepe University, Afyonkarahisar, Turkey
}

\begin{abstract}
Objectives: This study aims to investigate the association of two common HTR2A gene polymorphisms, rs6313 (102 T/C) and rs6311 (1438 A/G), with chronic low back pain (CLBP) and the pain threshold, disability, and sex differences.

Patients and methods: A total of 121 patients ( 40 males, 81 females; mean age $36.8 \pm 9.9$ years; range 18 to 50 years) having CLBP and 91 healthy controls ( 26 males, 65 females; mean age $34.1 \pm 10.2$ years; range 18 to 55 years) were included. Pressure pain thresholds (PPTs) of all participants were examined with manual algometer in certain sites of their body.

Results: The PPTs were all decreased in CLBP patients $(p<0.05)$. Although PPTs were lower in healthy female individuals, there was no sex difference regarding PPTs in CLBP patients ( $p>0.05)$. rs6311 polymorphism of HTR2A gene was associated with CLBP ( $p<0.05)$. In rs6313 polymorphism, at least one copy of $\mathrm{T}$ carriers and in rs6311 polymorphism, at least one copy of $\mathrm{G}$ carriers showed higher disability.

Conclusion: The PPT decreases in CLBP patients similar to other chronic pain conditions without any sex difference. Although rs6311 single nucleotide polymorphism of HTR2A gene was associated with CLBP and rs6313 polymorphism was not, rs6311 might have a protective effect on disability of these patients.

Keywords: Back pain; gene polymorphism; pain threshold; serotonin.
\end{abstract}

Low back pain, whether with sciatica or not, is a common global health problem and accounts for a large percentage of health expenses. ${ }^{1}$ In most cases, the underlying pathology can not be determined and so is called as 'non-specific low back pain'. Although the majority of patients improve within six weeks, $15 \%$ of patients continue to report severe pain one year after the first episode. ${ }^{2}$ The recurrence or chronicity of low back pain has a negative impact on these patients as it impairs both physical functioning and quality of life. ${ }^{3}$

Previous researches mainly focused on the etiology of low back pain. However, a limited number of studies emphasized on the perception of pain and pain threshold of patients with chronic low back pain (CLBP). ${ }^{4,5}$ The association between high pain sensitivity in chronic pain conditions including low back pain was investigated, and it was reported that the pressure pain threshold (PPT) decreased due to long lasting pain., ${ }^{4,6}$ One of the proposed mechanisms of pain sensitivity was sensitization of the central nervous system. ${ }^{5}$ The serotoninergic system, and the 5-hydroxytryptamine $(5-\mathrm{HT})$ as the key neurotransmitter, has an antinociceptive role in the dorsal horn of the descending tract of the spinal cord. ${ }^{7}$ A previous research reported the association between serotonin receptor 2A (HTR2A) gene polymorphisms and the susceptibility to chronic pain conditions such as fibromyalgia and chronic widespread 
pain. ${ }^{8}$ Indeed, serotonin specific reuptake inhibitors have been successfully used to treat CLBP. ${ }^{9,10}$ Moreover, it was reported that an important portion of CLBP patients have concomitant fibromyalgia. ${ }^{11}$ However, to date, the abnormalities in the serotonergic system and the variation in genes that are involved in 5 -HT synthesis and potentially associated with the extent of the pain have not been studied in patients with CLBP.

In this study, we aimed to investigate the association of two common HTR2A gene polymorphisms, rs6313 (102 T/C) and rs6311 (1438 A/G), with CLBP and the pain threshold, disability, and sex differences.

\section{PATIENTS AND METHODS}

The study was conducted at Medical Faculty of Afyon Kocatepe University, Afyonkarahisar, between October 2012 and April 2013 and included 121 patients (40 males, 81 females; mean age $36.8 \pm 9.9$ years; range 18 to 50 years) having low back pain for at least three months, as well as 91 pain free healthy controls (26 males, 65 females; mean age $34.1 \pm 10.2$ years; range 18 to 55 years).

Patients with accompanying sensory and/or motor neurologic deficits in lower extremities, history of lumbar surgery, history of inflammatory, traumatic or infectious diseases involving lower back, fibromyalgia, major depressive disorder, chronic widespread pain syndrome, and bipolar disorder were excluded.

Demographic characteristics of all individuals including age, sex, height, weight, and bodymass indexes were noted. The patient group was evaluated with the Oswestry disability index (ODI). ODI is a widely used scale for measuring disability in patients with low back pain, and its Turkish version is validated. ${ }^{12}$ The PPTs were examined with manual algometer in the following sites: (i) the middle point of the dorsum of the forearm; (ii) the middle point of the upper trapezius muscle; and (iii) paravertebral muscles at L1, L3, and L5 levels were examined bilaterally. The mean of three attempts was taken into consideration. The mean value of PPTs measured at bilateral sides was used for analysis.
All participants (or their responsible next of kin) provided a written informed consent and were studied under a protocol approved by the local medical ethics committee. The study was conducted in accordance with the principles of the Declaration of Helsinki. Approximately $2 \mathrm{~mL}$ aliquots of peripheral blood samples were collected from the participants and stored in ethylenediaminetetraacetic acid-coated vacutainers. Genomic deoxyribonucleic acid (DNA) was extracted from a $200 \mathrm{~mL}$ peripheral blood sample using a High Pure Template Preparation (Roche Diagnostics, Mannheim, Germany) kit. Then, DNA amount and DNA purity were quantified for each DNA sample by Nanodrop ND-1000 spectrophotometer V 3.7. DNA samples were stored at $-20{ }^{\circ} \mathrm{C}$ until use.

Each genomic DNA sample was analyzed for rs6313 and rs6311 polymorphisms of HTR2A gene. HTR2A genotyping was carried out by a real-time polymerase chain reaction (PCR) on a LightCycler $^{\circledR} 480$ Real-Time PCR System (Roche Diagnostics, Vienna, Austria) using LightCycler ${ }^{\circledR}$ FastStart DNA Master HybProbe (Roche Diagnostics, Mannheim, Germany), LightSNIP rs6311 HTR2A and LightSNIP rs6313 HTR2A Reagent Mix (Tib Molbiol, Berlin, Germany).

Amplicon was determined with fluorescence using specific probes that hybridize at the annealing phase of PCR cycle. After preparation of the master mixture $(1.0 \mathrm{~mL}$ Reagent Mix, $2.0 \mathrm{~mL}$ FastStart DNA Master HybProbe, $1.6 \mathrm{~mL}$ $25 \mathrm{mM} \mathrm{MgCl} 2$ and $13.4 \mathrm{~mL}$ sterile PCR-grade $\mathrm{H}_{2} \mathrm{O}$ ), $18 \mathrm{~mL}$ of the reaction mixture and $2 \mathrm{~mL}$ of the isolated genomic DNA template or the control template were loaded to 96-well plate for PCR analysis. For negative control, a sterile PCR-grade $\mathrm{H} 2 \mathrm{O}$ was added instead of a template.

All real-time PCRs were performed on a LightCycler 480 Real-Time PCR System under the following thermocycling conditions: 10 seconds at $95{ }^{\circ} \mathrm{C}$ for DNA denaturation, followed by 45 cycles of PCR (10 seconds denaturation at $95^{\circ} \mathrm{C}$, 10 seconds annealing at $60{ }^{\circ} \mathrm{C}$, and 15 seconds extension at $72{ }^{\circ} \mathrm{C}$ ). After the PCR, a melting curve analysis was performed by heating to $95^{\circ} \mathrm{C}$ for 20 seconds, followed by cooling to $40{ }^{\circ} \mathrm{C}$ for 20 seconds to achieve maximum hybridization and then heating slowly at $0.2{ }^{\circ} \mathrm{C} / \mathrm{second}$ to $85^{\circ} \mathrm{C}$. After the melting curve analysis, a final cooling 


\begin{tabular}{|c|c|c|c|c|c|}
\hline & \multicolumn{2}{|c|}{ CLBP group $(n=121)$} & \multicolumn{2}{|c|}{ Control group $(\mathrm{n}=91)$} & \multirow[b]{2}{*}{$p$} \\
\hline & $\mathrm{n}$ & Mean \pm SD & $\mathrm{n}$ & Mean \pm SD & \\
\hline Sex & & & & & 0.486 \\
\hline Female & 81 & & 65 & & \\
\hline Male & 40 & & 26 & & \\
\hline Age (year) & & $36.8 \pm 9.9$ & & $34.1 \pm 10.2$ & 0.063 \\
\hline Body mass index & & $27.7 \pm 5.0$ & & $26.3 \pm 5.6$ & 0.061 \\
\hline Forearm pressure pain threshold & & $7.2 \pm 2.1$ & & $7.7 \pm 2.1$ & 0.089 \\
\hline Trapezius pressure pain threshold & & $5.6 \pm 2.2$ & & $7.0 \pm 2.4$ & $<0.001$ \\
\hline L1 Paravertebral pressure pain threshold & & $6.9 \pm 2.3$ & & $8.1 \pm 2.1$ & $<0.001$ \\
\hline L3 Paravertebral pressure pain threshold & & $6.9 \pm 2.3$ & & $8.0 \pm 2.2$ & $<0.001$ \\
\hline L5 Paravertebral pressure pain threshold & & $6.9 \pm 2.4$ & & $8.0 \pm 2.1$ & $<0.001$ \\
\hline Visual analog scale for pain & & $59.7 \pm 16.6$ & & - & \\
\hline Oswestry disability index for low back pain & & $46.3 \pm 16.8$ & & - & \\
\hline
\end{tabular}

was carried out at $40{ }^{\circ} \mathrm{C}$ for 30 seconds. The fluorescence signals recorded in the respective channels were then converted to melting peaks by plotting the negative derivative of the fluorescence with respect to the temperature ( $2 \mathrm{dF} / \mathrm{dT}$ vs $\mathrm{T})$.

The resulting melting peaks in the different fluorescence channels allowed us to discriminate among the homozygous as well as the heterozygous genotypes. Melting temparature values were obtained for each allele of polymorphisms: 60.64 ${ }^{\circ} \mathrm{C}$ for AA; $60.64{ }^{\circ} \mathrm{C}$ and $68.48{ }^{\circ} \mathrm{C}$ for AG; 68.48 ${ }^{\circ} \mathrm{C}$ for GG; and $59.31{ }^{\circ} \mathrm{C}$ for TT; $59.31{ }^{\circ} \mathrm{C}$ and $63.98{ }^{\circ} \mathrm{C}$ for TC; $63.98{ }^{\circ} \mathrm{C}$ for $\mathrm{CC}$.

\section{Statistical analysis}

Statistical data were analyzed using SPSS version 15.0 (SPSS Inc., Chicago, IL, USA) for Windows. Descriptive statistics are given as mean \pm standard deviation. Kolmogorov-Smirnov test was used to determine the normality of the distribution of the variables. Student's t-test or Mann-Whitney $U$ tests were used to measure the differences between two variables, where appropriate. In patients and controls, allele and genotypic frequencies related to HTR2A gene rs6313 and rs6311 polymorphisms were compared using Chi-square test.

\section{RESULTS}

The demographic and clinical data and corresponding significance level of the difference between two groups are shown in Table 1.

The amount of pain reported and disabilities present in CLBP patients, and PPT measurements in female and male individuals both in CLBP and control groups are outlined

Table 2. Pressure pain thresholds, visual analog scale for pain, and Oswestry disability index scores in female and male individuals

\begin{tabular}{|c|c|c|c|c|c|c|}
\hline & \multicolumn{3}{|c|}{ CLBP group } & \multicolumn{3}{|c|}{ Control group } \\
\hline & Female & Male & & Female & Male & \\
\hline & Mean \pm SD & Mean \pm SD & $p$ & Mean \pm SD & Mean \pm SD & $p$ \\
\hline Forearm pressure pain threshold & $7.0 \pm 2.2$ & $7.7 \pm 1.9$ & 0.045 & $7.1 \pm 2.0$ & $9.3 \pm 1.3$ & $<0.001$ \\
\hline Trapezius pressure pain threshold & $5.5 \pm 2.3$ & $5.7 \pm 2.0$ & 0.696 & $6.5 \pm 2.3$ & $8.5 \pm 2.2$ & $<0.001$ \\
\hline L1 Paravertebral pressure pain threshold & $6.7 \pm 2.2$ & $7.3 \pm 2.4$ & 0.167 & $7.6 \pm 2.1$ & $9.5 \pm 1.4$ & $<0.001$ \\
\hline L3 Paravertebral pressure pain threshold & $6.8 \pm 2.1$ & $7.3 \pm 2.6$ & 0.214 & $7.4 \pm 2.2$ & $9.4 \pm 1.5$ & $<0.001$ \\
\hline L5 Paravertebral pressure pain threshold & $6.7 \pm 2.3$ & $7.2 \pm 2.6$ & 0.280 & $7.6 \pm 2.2$ & $9.5 \pm 1.2$ & $<0.001$ \\
\hline Visual analog scale for pain & $60.5 \pm 17.7$ & $58.0 \pm 14.0$ & 0.439 & - & - & \\
\hline Oswestry disability index for low back pain & $50.6 \pm 16.0$ & $38.0 \pm 15.3$ & $<0.001$ & - & - & \\
\hline
\end{tabular}


Table 3. Genotype and allele frequencies of HTR2A gene $102 \mathrm{~T} / \mathrm{C}$ polymorphism in chronic low back pain and control groups

\begin{tabular}{|c|c|c|c|c|c|c|}
\hline & \multicolumn{2}{|c|}{ CLBP group $(n=121)$} & \multicolumn{2}{|c|}{ Control group $(n=91)$} & \multirow[b]{2}{*}{$p$} & \multirow[b]{2}{*}{ OR $(95 \% \mathrm{CI})$} \\
\hline & $\mathrm{n}$ & $\%$ & $\mathrm{n}$ & $\%$ & & \\
\hline TT & 36 & 29.8 & 27 & 29.7 & & \\
\hline TC & 51 & 42.1 & 49 & 53.8 & 0.103 & \\
\hline $\mathrm{CC}$ & 34 & 28.1 & 15 & 16.5 & & \\
\hline TTTC & 87 & 71.9 & 76 & 16.5 & 0.050 & $1.980(1.002-3.912)$ \\
\hline \multicolumn{7}{|l|}{ Allele } \\
\hline $\mathrm{T}$ & 123 & 50.8 & 103 & 56.6 & \multirow{3}{*}{0.238} & \multirow{3}{*}{$1.261(0.857-1.856)$} \\
\hline $\mathrm{C}$ & 119 & 49.1 & 79 & 43.4 & & \\
\hline HWE & \multicolumn{2}{|c|}{0.085} & \multicolumn{2}{|c|}{0.360} & & \\
\hline
\end{tabular}

in Table 2. Although all of the PPT assessments were lower in female controls compared to males, the PPTs were similar in female and male CLBP patients.

In the $102 \mathrm{~T} / \mathrm{C}$ polymorphism of the HTR2A gene, the base in nucleotide position 102 may be thymine $(\mathrm{T})$ or cytosine $(\mathrm{C})$, with three possible genotypes as TT, TC or CC. These polymorphisms were evaluated in the patients diagnosed with CLBP and the healthy controls. The genotype distribution in each group was in accordance with the Hardy-Weinberg equilibrium ( $p>0.05)$. Table 3 shows the distribution of the genotype and allele frequencies of $102 \mathrm{~T} / \mathrm{C}$ in both groups. The differences were not statistically significant between the two groups ( $p>0.05$ for each).

Table 4 shows the distribution of the genotype and allele frequencies of $1438 \mathrm{~A} / \mathrm{G}$ in both CLBP and control groups. There were significant differences between the two groups in terms of genotype frequencies $(p<0.05)$. However, the differences in allele frequencies were not significant between the groups ( $p>0.05)$.

Furthermore, the patients and controls were subdivided into two groups based on the presence of the polymorphism. With regards to rs6313 (102 T/C) polymorphism, patients carrying at least one copy T (TT or TC genotypes) had higher ODI scores compared to CC genotype carriers $(48.1 \pm 16.7$ vs $41.6 \pm 16.3, p=0.046)$. The analysis of CC genotype and the genotypes including $\mathrm{T}$ allele, which is associated with higher ODI score, revealed that the percentage of genotypes including $\mathrm{T}$ allele was higher in CLBP group $(p=0.05)$ (Table 3). The PPTs measured in all sites were similar $(p>0.05)$. There was no significant difference between the individuals carrying at least one copy of $\mathrm{C}$ (CC and TC) and TT genotypes in all study parameters $(\mathrm{p}>0.05)$.

With regards to rs6311 (1438 A/G) polymorphism, a comparison of the individuals carrying at least one copy of A (AA and AG) and GG revealed that the ODI score was significantly

Table 4. Genotype and allele frequencies of HTR2A gene 1438 A/G polymorphism in chronic low back pain and control groups

\begin{tabular}{|c|c|c|c|c|c|c|}
\hline & \multicolumn{2}{|c|}{ CLBP group $(\mathrm{n}=121)$} & \multicolumn{2}{|c|}{ Control group $(\mathrm{n}=91)$} & \multirow[b]{2}{*}{$p$} & \multirow[b]{2}{*}{ OR $(95 \% \mathrm{CI})$} \\
\hline & $\mathrm{n}$ & $\%$ & $\mathrm{n}$ & $\%$ & & \\
\hline$\overline{\mathrm{AA}}$ & 36 & 29.8 & 28 & 30.8 & \multirow{3}{*}{0.043} & \\
\hline$A G$ & 51 & 42.1 & 50 & 54.9 & & \\
\hline GG & 34 & 28.1 & 13 & 14.3 & & \\
\hline \multicolumn{7}{|l|}{ Allele } \\
\hline $\mathrm{T}$ & 123 & 50.8 & 106 & 58.2 & \multirow{3}{*}{0.129} & \\
\hline $\mathrm{C}$ & 119 & 49.2 & 76 & 41.8 & & 0741 (0 5031 092 \\
\hline HWE & \multicolumn{2}{|c|}{0.085} & \multicolumn{2}{|c|}{0.216} & & $0.141(0.000-1.092$ \\
\hline
\end{tabular}


higher in at least one A carriers $(48.2 \pm 16.1$ vs $41.5 \pm 16.4, p=0.045)$. The PPTs were not significantly different between groups. There was no significant difference between individuals carrying at least one copy of $\mathrm{G}$ (AG and GG) and AA genotypes in all study parameters $(p>0.05)$.

\section{DISCUSSION}

This study was conducted to evaluate the PPT, disability, and the differences among sexes in CLBP patients and the association of CLBP with 5-HTR rs6313 and rs6311 gene polymorphisms. The major findings were as follows: (i) PPTs were decreased in CLBP patients. (ii) Although PPTs were lower in healthy female individuals, there was no sex difference regarding PPTs in CLBP patients. (iii) In rs6313 polymorphism, at least one copy of $\mathrm{T}$ carriers had higher disability, and in rs6311 polymorphism, at least one copy of $\mathrm{G}$ carriers had higher disability. To the best of our knowledge, the current study is the first evaluating the association between HTR2A gene polymorphisms in a cohort of CLBP patients.

In the study by Neziri et al., ${ }^{13}$ pressure pain detection threshold and pressure pain tolerance thresholds at the site of most severe pain were found as discriminative in diagnosis of pain hypersensitivity and identifying individuals having risk to develop CLBP over time. PPT was found to decrease as a result of CLBP; however, it was not detected as a predisposing factor for the development of low back pain in the follow-up study by O'Neill et al. ${ }^{6}$ Furthermore, in the study conducted by Imamura et al., ${ }^{5}$ PPT values of myotomes, sclerotomes and dermatomes between L1 and S3 segments were evaluated and lower PPT values were reported in CLBP patients. They proposed that the hyperalgesia in the painful area may be a result of several mechanisms such as central nervous system sensitization. Likewise, in the current study, hyperalgesia was detected at painful areas (L1, L3, and L5 paravertebral muscles) and also at irrelevant sites as forearm and trapezius muscles in CLBP patients. Consequently, hyperalgesia is a common finding in CLBP patients; however, the evidence does not support that lower PPT predisposes to low back pain or affects its chronicity. Apart from previous studies, we investigated the sex differences regarding PPT in CLBP patients. Although female individuals had lower PPT at all sites in pain free controls, the PPT values of both female and male CLBP patients were lower compared to controls and there was no difference between female and male patients. The PPT was not affected by sex in this chronic pain condition. Since, to our knowledge, sex differences in PPT values in CLBP patients were not studied before, we are unable to compare our results with previous studies.

In the study investigating the association of 5-HT with sciatic pain in patients with lumbar disc herniation in an animal model, the exogeneous 5-HT induced pain related behaviors after it was injected to the nerve root. Thus, it was concluded that 5-HT plays a role in early biochemical pathogenesis of sciatic pain. ${ }^{14}$ Furthermore, the treatment of patients with lumbar disc herniation with 5-HT2A receptor antagonists revealed similar efficacy with non-steroidal anti-inflammatory drugs. ${ }^{10}$ Kanayama et al. ${ }^{9}$ studied the efficacy of 5-HT2A receptor antagonists in patients with symptomatic lumbar disc herniation with and without disc extrusion. They reported that the 5-HT2A receptor antagonists were effective in treatment of patients without disc extrusion while they were not effective in patients with extruded disc. The gene HTR2A, which codes for the 5HT2A receptor, is located on chromosome 13q14-q21 and contains three exons and two introns spanning $20 \mathrm{~kb} \cdot{ }^{15,16}$ The rs6313 single nucleotide polymorphism (SNP) was found to be associated with fibromyalgia, depression, chronic fatigue syndrome, and chronic widespread pain syndrome. ${ }^{8,17-20}$ Depression is a common form of psychological disturbance seen in patients with CLBP, and it is an important factor associated with disability in this patient cohort. ${ }^{21,22}$ The patients with a history of major depressive disorder, chronic widespread pain syndrome, and fibromyalgia were excluded from this study, thus the findings may not be attributable to these disorders. According to the results of the current study, there was a significant difference in rs6311 genotype distribution; however, no difference was detected with regards to rs6313 SNP. Furthermore, at least one copy of $\mathrm{T}$ carriers in rs6313 (102 T/C) polymorphism, and at least 
one copy of $\mathrm{G}$ carriers in rs6311 (1438 A/G) polymorphism showed worse disability scores.

Accordingly, of the SNPs in HTR2A gene, the rs6311 (1438 A/G) was associated with CLBP, but the patients carrying at least one A allele had higher disability. The rs6313 (102 T/C) is not associated with CLBP and at least one $\mathrm{T}$ carriers have higher disability. Therefore, the disability in CLBP cannot be explained with $G$ and $C$ alleles in these gene polymorphisms. Instead the disability might be due to accompanying disorders such as depression or chronic widespread pain.

This study has a few limitations. Firstly, for detecting pain sensitivity, we only used PPT. Different quantitative sensory tests including, heat, cold, and electrical stimulation might also be used. Secondly, we investigated rs6311 and rs6313, which are common SNPs in HTR2A gene, and other SNPs in this gene may be studied in future researches. Finally, our patient cohort is relatively small and further studies with higher number of patients and controls might be more representative.

In conclusion, the pain threshold decreases in CLBP patients similar with other chronic pain conditions. Interestingly, there is no sex difference with regards to PPT in CLBP patients. rs6311 SNP of HTR2A gene is associated with CLBP; however, it is negatively associated with disability due to CLBP. This polymorphism might have a protective effect for disability in CLBP patients. It seems that rs6313 polymorphism has no significant effect on CLBP susceptibility. Studies with a larger sample sizes are needed to confirm or amend these results.

\section{Acknowledgements}

The authors thank Afyon Kocatepe University Foreign Language Support Unit for their assistance in editing this article.

\section{Declaration of conflicting interests}

The authors declared no conflicts of interest with respect to the authorship and/or publication of this article.

\section{Funding}

The authors received no financial support for the research and/or authorship of this article.

\section{REFERENCES}

1. Cherkin DC, Deyo RA, Battié M, Street J, Barlow W. A comparison of physical therapy, chiropractic manipulation, and provision of an educational booklet for the treatment of patients with low back pain. N Engl J Med 1998;339:1021-9.

2. Von Korff M, Saunders K. The course of back pain in primary care. Spine (Phila Pa 1976) 1996;21:2833-7.

3. Hong JH, Kim HD, Shin HH, Huh B. Assessment of depression, anxiety, sleep disturbance, and quality of life in patients with chronic low back pain in Korea. Korean J Anesthesiol 2014;66:444-50.

4. Rabey M, Slater H, O'Sullivan P, Beales D, Smith A. Somatosensory nociceptive characteristics differentiate subgroups in people with chronic low back pain: a cluster analysis. Pain 2015;156:1874-84.

5. Imamura M, Chen J, Matsubayashi SR, Targino RA, Alfieri FM, Bueno DK, et al. Changes in pressure pain threshold in patients with chronic nonspecific low back pain. Spine (Phila Pa 1976) 2013;38:2098-107.

6. O'Neill S, Manniche C, Graven-Nielsen T, ArendtNielsen L. Generalized deep-tissue hyperalgesia in patients with chronic low-back pain. Eur J Pain 2007;11:415-20.

7. Mense S. Neurobiological concepts of fibromyalgia-the possible role of descending spinal tracts. Scand $\mathrm{J}$ Rheumatol Suppl 2000;113:24-9.

8. Nicholl BI, Holliday KL, Macfarlane GJ, Thomson W, Davies KA, O'Neill TW, et al. Association of HTR2A polymorphisms with chronic widespread pain and the extent of musculoskeletal pain: results from two population-based cohorts. Arthritis Rheum 2011;63:810-8.

9. Kanayama M, Hashimoto T, Shigenobu K, Yamane S. Efficacy of serotonin receptor blocker for symptomatic lumbar disc herniation. Clin Orthop Relat Res 2003;411:159-65.

10. Kanayama M, Hashimoto T, Shigenobu K, Oha F, Yamane S. New treatment of lumbar disc herniation involving 5-hydroxytryptamine2A receptor inhibitor: a randomized controlled trial. J Neurosurg Spine 2005;2:441-6.

11. Yağcı İ, Akcan E, Yıldırım P, Ağırman M, Güven Z. Fibromyalgia Syndrome in Patients with Chronic Low Back Pain. Turk J Rheumatol 2010;25:37-40.

12. Yakut E, Düger T, Oksüz C, Yörükan S, Ureten K, Turan D, et al. Validation of the Turkish version of the Oswestry Disability Index for patients with low back pain. Spine (Phila Pa 1976) 2004;29:581-5.

13. Neziri AY, Curatolo M, Limacher A, Nüesch E, Radanov B, Andersen OK, et al. Ranking of parameters of pain hypersensitivity according to their discriminative ability in chronic low back pain. Pain 2012;153:2083-91.

14. Kato K, Kikuchi S, Konno S, Sekiguchi M. Participation of 5-hydroxytryptamine in pain-related behavior induced by nucleus pulposus applied on the nerve 
root in rats. Spine (Phila Pa 1976) 2008;33:1330-6.

15. Hsieh CL, Bowcock AM, Farrer LA, Hebert JM, Huang $\mathrm{KN}$, Cavalli-Sforza LL, et al. The serotonin receptor subtype 2 locus HTR2 is on human chromosome 13 near genes for esterase D and retinoblastoma-1 and on mouse chromosome 14. Somat Cell Mol Genet 1990;16:567-74.

16. Chen K, Yang W, Grimsby J, Shih JC. The human 5-HT2 receptor is encoded by a multiple intron-exon gene. Brain Res Mol Brain Res 1992;14:20-6.

17. Tander B, Gunes S, Boke O, Alayli G, Kara N, Bagci $\mathrm{H}$, et al. Polymorphisms of the serotonin-2A receptor and catechol-O-methyltransferase genes: a study on fibromyalgia susceptibility. Rheumatol Int 2008;28:685-91.

18. Eley TC, Sugden K, Corsico A, Gregory AM, Sham P, McGuffin P, et al. Gene-environment interaction analysis of serotonin system markers with adolescent depression. Mol Psychiatry 2004;9:908-15.

19. Smith AK, Dimulescu I, Falkenberg VR, Narasimhan S, Heim C, Vernon SD, et al. Genetic evaluation of the serotonergic system in chronic fatigue syndrome. Psychoneuroendocrinology 2008;33:188-97.

20. Mergener M, Becker RM, dos Santos AF, dos Santos $\mathrm{GA}$, de Andrade FM. Influence of the interaction between environmental quality and T102C SNP in the HTR2A gene on fibromyalgia susceptibility. Rev Bras Reumatol 2011;51:594-602.

21. Sagheer MA, Khan MF, Sharif S. Association between chronic low back pain, anxiety and depression in patients at a tertiary care centre. J Pak Med Assoc 2013;63:688-90.

22. Hung CI, Liu CY, Fu TS. Depression: An important factor associated with disability among patients with chronic low back pain. Int $\mathrm{J}$ Psychiatry Med 2015;49:187-98. 